\title{
Correlações entre Dimensões da Qualidade das Amizades e Autopercepção em Crianças ${ }^{1}$
}

\author{
Luiza Maria da Rocha Zunino ${ }^{a}$, Edi Cristina Manfroi ${ }^{b}$, Sandra Adriana Neves Nunes ${ }^{c}$, \\ Ana Maria Xavier Faraco ${ }^{a}$, Mauro Luís Vieira ${ }^{* a}$ \& Kenneth H. Rubin ${ }^{d}$ \\ ${ }^{a}$ Universidade Federal de Santa Catarina, Florianópolis, Brasil, ${ }^{b}$ Universidade Federal da Bahia, Vitória da Conquista, Brasil, \\ ${ }^{\mathrm{c}}$ Faculdade de Ilhéus, Ilhéus, Brasil \& ${ }^{\mathrm{d}}$ University of Maryland, College Park, USA
}

\begin{abstract}
RESUMO
No presente estudo foram examinadas correlações entre dimensões qualitativas da amizade e da autopercepção em crianças de 9 a 13 anos de idade. Os dados derivaram de dois questionários aplicados a 158 crianças $(52,5 \%$ meninos $)$ em duas escolas públicas. Os resultados indicaram que: a) crianças que identificam nas suas relações de amizade uma fonte de apoio tendem a se perceber acadêmica e atleticamente competentes e bem aceitas socialmente; b) crianças que encontram nas amizades um espaço privilegiado para resolver conflitos e buscar intimidade e validação de seus sentimentos também têm percepções positivas acerca de si mesmas, e c) o gênero e a idade da criança tiveram influências diferenciadas nas dimensões da qualidade das amizades e da autopercepção.

Palavras-chave: dimensões qualitativas da amizade; autopercepção; bem-estar social e psicológico de crianças.
\end{abstract}

\begin{abstract}
Correlations between friendship quality dimensions and self-perception in children

In the present study, correlations between friendship's quality dimensions and self-perception were examined in children (9-13 years-old). Data derived from two questionnaires administered to 158 children (52.5\% boys) from two public schools. Results indicated that: a) children who identify, in their friendship relations, a source of support perceived themselves as academically and athletically competent and socially well accepted; b) children who perceived their friendship relations as a privileged space for solving conflicts, for intimacy, validation and care have also a positive perceptions of themselves, and c) the child's age and gender had different influences on dimensions of self-perception and friendships quality.

Keywords: friendship qualitative dimensions; self-perception; child social and psychological well-being.
\end{abstract}

À medida que as crianças crescem, elas são gradualmente inseridas em outros grupos de socialização (vizinhos, colegas da escola, etc.) que passam a exercer também função socializadora, antes mais relacionada com a família. Por exemplo, o ambiente escolar permite à criança entrar em contato com a vida social e pública. A criança passa a se identificar com companheiros da mesma idade - os pares - em vez de se comparar-se aos indivíduos adultos, normalmente da família, e dos quais depende (Osterrieth, 1980). É nesse ponto que as relações de convivência com outras crianças iguais a ela, gradualmente, passam a ser tão importantes quanto as familiares. Além disso, a sociedade ocidental atual, altamente urbanizada e com famílias reduzidas, tem adiantado o ingresso da criança na escola, aumentando sua convivência com os pares, os quais, na passagem da infância para a adolescência, passam a ocupar um papel central no desenvolvimento social do indivíduo (Garcia, 2005).

\section{NATUREZA ESTRUTURAL E FUNCIONAL DA AMIZADE}

Na convivência com seus pares, a criança estabelece relações sociais de diferentes níveis de complexidade, variando das mais simples, como interações de colegas em função de atividades comuns na escola ou em outro ambiente social, até as mais complexas

\footnotetext{
Endereço para correspondência: Mauro Luís Vieira - maurolvieira@gmail.com.
} 
como as relações de amizade. Nesse estudo, parte-se do pressuposto de que as relações de têm contribuição marcante no desenvolvimento infantil. No entanto, em função de vários tipos de interação que a criança estabelece no ambiente social, é necessário especificar a natureza das relações de amizade. Uma das definições atuais para esse fenômeno, e adotada para este estudo caracteriza amizade como uma relação diádica, bilateral, próxima, mútua e voluntária, baseada no senso de reciprocidade e de igualdade entre os indivíduos $(\mathrm{Ru}-$ bin, Coplan, Chen, Buskirk, \& Wojslawowicz, 2005).

Ainda em termos estruturais, existem sutilezas que precisam ser compreendidas para se avaliar a qualidade da amizade. Por exemplo, Parker e Asher (1993) consideram cinco aspectos que revelam qualidade positiva da amizade: 1) Validação e cuidado, caracterizado por cuidado mútuo, apoio, e interesse; 2) Companhia e recreação, que se refere ao tempo agradável que os amigos passam juntos dentro ou fora da escola; 3) Ajuda e direção, como, por exemplo, os esforços dos amigos para ajudar uns aos outros (instrumentalmente) com tarefas de rotina ou desafios; 4) Abertura intima (intimidade), caracterizada pela revelação de informações pessoais e sentimentos; e 5) Resolução de conflito, caracterizada pelo grau com que desentendimentos na relação são resolvidos de forma eficiente e justa. Com relação aos aspectos que denotam qualidade negativa da amizade, os autores destacam o conflito e a traição, os quais são caracterizados por discussões, brigas, desacordos, aborrecimento e desconfiança. Além disso, a qualidade da amizade está associada a índices de ajustamento e funcionamento psicossocial saudável, como a autoestima (Garcia, 2005) e a motivação para o esporte (Fitzgeral, Fitzgerald \& Aherne, 2012; Smith, Ullrich-French, Walker, \& Hurley 2006). Ter um bom amigo pode ser uma maneira de prevenir o desenvolvimento de sentimentos negativos sobre a vida social (Rubin et al., 2005).

Talvez a função mais importante da amizade seja oferecer às crianças uma base de segurança extrafamiliar, que lhes possibilite explorar os efeitos de seus comportamentos em si mesmas, em seus pares e em seus ambientes sociais (Rubin et al., 2005). Entretanto, os autores também descrevem funções mais específicas desse tipo de relacionamento como: (a) fornecimento de apoio, elevação da autoestima e a autoavaliação positiva; (b) promoção de segurança emocional; (c) fornecimento de afetos e possibilidade de autodesvendamento; (d) fornecimento de intimidade e afeto; (e) oferta de validação consensual de interesses, espe- ranças e medos; (f) fornecimento de assistência instrumental e informacional; (g) promoção do crescimento da sensibilidade interpessoal; e (h) oferecimento de modelos para futuros relacionamentos - namoros, casamentos e relações parentais.

As amizades afetam positivamente outras relações sociais no grupo de pares, podendo promover o aumento da aceitação social e minimizar as chances de rejeição grupal, abusos e de vitimização (Garcia, 2005). Em crianças que sofreram abuso ou rejeição pelos pares, a amizade pode contribuir reduzindo os estados de depressão e solidão. A esse respeito, Rubin et al. (2005) concluem que crianças rejeitadas internalizam suas dificuldades sociais com seus pares; relatam sentirem-se menos competentes, menos eficientes em suas habilidades sociais e insatisfeitas nos relacionamentos com os pares. Para os autores, a criança que se sente incompetente socialmente e que acredita que os outros não gostam dela pode desenvolver sentimentos de isolamento e solidão.

\section{INTERAÇÃO SOCIAL E QUALIDADE DAS AMIZADES}

Um dos fatores que influencia a interação social e a qualidade das amizades é o gênero da criança (Eder \& Hallinan, 1978; Parker \& Asher, 1993). Por exemplo, meninos e meninas preferem diferentes tipos de jogos e atividades, com números diferentes de participantes (Archer, 1992; Maccoby, 1988; Souza \& Rodrigues, 2002). Sutton-Smith e Rosenberg (1971), em sua pesquisa com sujeitos em idade entre 9 e 15 anos, obsevaram que a composiçao dos grupos de meninos tende a ter um número maior de participantes do que a dos grupos de meninas. Os resultados da pesquisa revelaram que os meninos participavam de atividades que exigiam habilidades físicas e as meninas mostraram preferência por jogos de estratégia. Cada uma dessas modalidades de interação tende a revelar qualidades distintas que orientam a formação de laços de amizade; a primeira baseada no respeito à destreza física e a busca pela dominância grupal e a segunda na valorização à habilidade comunicacional, por exemplo. Em outro estudo, Eder e Hallinan (1978) constataram que amizades diádicas entre meninas tendem a ser mais exclusivas do que as entre meninos. Ou seja, meninos tendem a alternar mais entre as relações de amizade que estabelecem com os membros num determinado grupo de pares.

Embora as diferenças nos padrões de interação e de amizade entre crianças pareçam ser, inicialmente, 
devido às características dos grupos, é provável que, uma vez formadas, as amizades promovam uma maior diferenciação nos padrões de interação, levando, por sua vez, ao desenvolvimento de diferentes tipos de habilidades sociais. Por exemplo, o fato de os jogos masculinos encorajarem os meninos a desenvolver amizades não exclusivas e aumentar a tendência dos garotos para interações sociais em grupos mais numerosos exigem o desenvolvimento de habilidades sociais específicas como tomada de decisão em grupo, liderança entre outras. Por outro lado, a tendência ao desenvolvimento de amizades mais exclusivas entre as meninas aumenta a tendência de interagir em díades e leva ao desenvolvimento de outros tipos de competências sociais, tais como a capacidade de estabelecer intimidade e autodesvendamento (Archer, 1992; Eder \& Hallinan, 1978).

Além disso, segundo Archer (1992), meninos se envolvem em jogos turbulentos, brigam mais e mostram interações mais abertamente dominantes. $\mathrm{O}$ jogo das meninas, por outro lado, é caracterizado por ser mais cooperativo, enfatizando uma forte convenção de troca da palavra entre os interlocutores ("tomada de palavra") o que está consoante com outros estudos (Maccoby, 1988) que indicam que as meninas utilizam a fala, principalmente, para manter interações amigáveis e para criar e manter relações estreitas com base na igualdade e justiça. Meninas frequentemente expressam concordância com ideias de outras pessoas, dão chance para que as outras meninas falem e reconhecem o que os outros falam na elaboração de sua fala. Os meninos, ao contrário, usam a fala para reforçar seu status, para atrair e manter a audiência e como autoafirmação quando outros estão falando. Comparados com as meninas, os meninos interrompem uns aos outros mais frequentemente, usam comandos, ameaças e demonstram autoridade e, muitas vezes, recusam-se a respeitar as demandas de outras crianças.

\section{INFLUÊNCIA DA QUALIDADE DA AMIZADE NA AUTOPERCEPÇÃO}

Outro aspecto a considerar é a influência das amizades na percepção que a criança tem a respeito dela própria. Ou seja, no início do desenvolvimento, os adultos eram as referências para a criança estabelecer sua identidade. Contudo, a partir dos anos escolares os colegas passam a desempenhar papel importante na formação de sua personalidade e na percepção de suas competências (Rubin et al., 2005). Assim, a autopercepção se refere aos atributos (características) do próprio indivíduo que conscientemente os reconhece e expressa através da linguagem, quando se descreve (Harter, 1999). Segundo esta autora, os termos autorpresentação, autopercepção e autodescrição podem ser usados como sinônimos.

Estudos também têm revelado diferenças entre meninos e meninas nas percepções a respeito de si mesmo, em diferentes competências. Estudos de Cole (1991), Hoge e McSheffrey (1990) e Villwock e Valentini (2007) indicaram que a percepção de competência atlética é mais positiva para os meninos. Neste último estudo, além dos meninos se perceberem mais competentes atleticamente eles também demonstraram mais competência no aspecto motor. Nos resultados de Almeida, Valentini e Berleze (2009), no entanto, não houve diferença para esta competência em relação ao gênero. Em relação à competência acadêmica, os achados de várias pesquisas (Biasoli-Alves \& Caldana, 1992; Carvalho, 2004; Perez \& Urquijo, 2001) têm sugerido que meninas são mais competentes academicamente do que meninos. Com relação à aceitação social, as diferenças de gênero são menos claras e as pesquisas têm apresentado resultados discordantes entre si. Por exemplo, enquanto Cecconello e Koller (2000) concluíram que meninas são mais habilidosas socialmente do que meninos, Mondell e Tyler (1981) não encontraram diferença significativa entre os gêneros, neste aspecto.

Em termos conceituais, não há como afirmar que os atributos que as crianças ou adolescentes usam para se autodescrever são livres de valência, pois, muito provavelmente eles têm um significado afetivo e, por isso, em algum ponto, enquadram-se no continuum da escala de avaliação do self tendo como referência o contexto grupal de que fazem parte (Harter, 1999). Entretanto, é importante diferenciar uma valência gerada a partir de uma avaliação que represente características globais do indivíduo (por exemplo: "Eu sou uma pessoa de valor"), daquela que reflete o sentido de adequação do indivíduo em domínios particulares como competência cognitiva, (por exemplo, "Eu sou esperto") e competência atlética ("Eu sou bom em esportes") e assim por diante (Harter, 1999). A partir disto, pode-se considerar a autopercepção, como um constructo psicológico complexo e multidimensional que espelha as percepções do sujeito de ser, ou não, competente, em diferentes domínios, independentes entre si (Harter, 1982).

Para esta pesquisa foram consideradas duas premissas fundamentais sobre a autopercepção. A primeira é de que esse conceito é um construto cognitivo e, 
portanto, as habilidades e limitações cognitivas de cada período do desenvolvimento servem de suporte para a maneira como a criança se percebe. A segunda considera que essa dimensão psicológica - a autopercepção - afeta e é afetada pela qualidade dos relacionamentos de amizade que a criança estabelece ao longo do seu desenvolvimento.

A despeito das evidências da relevância das amizades para o bem-estar psicológico do indivíduo (Parker \& Asher, 1993; Rubin et al., 2005), no Brasil, o interesse pela natureza e funções da amizade na infância e adolescência ainda é incipiente (Garcia, 2005) e existe uma lacuna na investigação de suas implicações para a autopercepção infantil. Conforme pode ser constatado pela revisão de literatura apresentada, não foram encontrados estudos no Brasil que tratassem da relação entre qualidade da amizade e autopercepção, envolvendo dimensões relacionadas aos dois constructos e de forma quantitativa. A maioria dos estudos dessa natureza vem da América do Norte e Europa, que são locais com grande produção científica na área. A partir desses estudos são realizadas afirmações que eventualmente podem ser generalizadas. No entanto, é necessário testar essas hipóteses em outros contextos.

Nesse sentido, estudos no Brasil que buscam compreender as distintas dimensões da autopercepção (competência acadêmica, atlética, aceitação social e avaliação global) e funções da qualidade das amizades se tornam relevantes, principalmente na pré-adolescência, período em que o indivíduo desenvolve o senso de identidade e que as relações de pares exercem papel importante nesse processo (Erikson, 1976).

\section{OBJETIVOS E HIPÓTESES DO ESTUDO}

A presente pesquisa tem como objetivo examinar as relações entre qualidade da amizade e autopercepção de crianças brasileiras no final da infância e início da adolescência. Além disso, o gênero da criança e a sua idade também serão fatores de interesse no estudo. Especificamente, foram investigadas as múltiplas relações entre três dimensões da qualidade da amizade (Ajuda instrumental/direção/companhia, Resolução de conflito/intimidade/validação e Conflito/traição) e três dimensões da autopercepção da criança (Competência Acadêmica, Aceitação Social e Competência Atlética).

Assim, devido à amizade ser uma fonte de segurança e autoestima, e com base na literatura sobre o fenômeno em estudo, espera-se que as dimensões positivas da qualidade da amizade correlacionem-se de forma positiva com as dimensões da autopercepção
(Parker \& Asher, 1993; Rubin et al., 2005). Além disso, espera-se que as variáveis sociodemográficas (sexo e idade das crianças) tenham efeitos significativos sobre a percepção da qualidade da amizade e sobre as diferentes dimensões da autopercepção. No que se refere à qualidade das amizades, espera-se que meninas terão escores mais altos do que meninos em resolução de conflito/intimidade/validação (Parker \& Asher, 1993). No mesmo sentido, espera-se que as meninas apresentem escores mais altos na dimensão ajuda instrumental/direção/companhia (Parker \& Asher, 1993), visto que tendem a ser mais cooperativas e valorizam mais o diálogo (Archer, 1992). Por outro lado, espera-se que os meninos apresentem escores mais altos em Conflito/traição, haja vista sua tendência a se envolverem em jogos turbulentos e brigas (Archer, 1992).

Com relação à autopercepção, é esperado que meninas tenham escores mais altos do que meninos na dimensão competência acadêmica (Biasoli-Alves \& Caldana,1992; Carvalho, 2004; Perez \& Urquijo, 2001) e meninos percebam-se como mais competentes atleticamente do que meninas (Cole, 1991; Hoge \& McSheffrey,1990; Villwock \& Valentini, 2007). Considerando os resultados inconclusivos de pesquisas, nenhuma hipótese direcional foi lançada com relação às diferenças de gênero para Aceitação social. Finalmente, é esperado que haja diferença na autopercepção das crianças de diferentes faixas etárias. Especificamente esperase que crianças mais jovens percebam-se como mais competentes academicamente (Almeida, Valentini \& Berleze, 2009) do que as mais velhas.

\section{MÉTODO}

\section{Participantes}

Participaram deste estudo 158 crianças $(52,5 \%$ meninos), com idades entre nove e 13 anos $(\mathrm{M}=$ 10,$29 ; \mathrm{DP}=0,81$, que frequentavam a $4^{\circ}$ série do ensino fundamental em duas escolas da rede pública da cidade de Florianópolis, Santa Catarina. A idade das mães foi em média de 38,22 (DP $=7,15)$ e dos pais $41,83(\mathrm{DP}=8,18)$. No momento da coleta, $27,3 \%$ das mães e $27,2 \%$ dos pais possuíam ensino superior ou pós-graduação completo ou incompleto. No entanto, a maioria dos pais (72,6\% das mães e 70,2\% dos pais) possuía ensino fundamental incompleto ou completo.

\section{Instrumentos}

Os questionários utilizados neste estudo são parte de uma bateria de medidas administrada às crianças 
das duas escolas que participaram do projeto "Relações de Amizade na Infância e Transição Ecológica na Região Sul do Brasil". Este projeto está vinculado a um projeto maior, internacional, desenvolvido por um consórcio de pesquisadores, denominado "International Consortium for the Sudy of Social and Emotional Development", sob a coordenação geral do Professor Kenneth H. Rubin, da Universidade de Maryland, USA. O objetivo deste projeto de parceria internacional é investigar, em diferentes culturas, o papel das relações parentais, das relações de pares, em geral, e das amizades, especificamente, no desenvolvimento psicossocial e na adaptação emocional de crianças que se encontram na transição da infância para a adolescência. Os trabalhos derivados desta parceria permitirão apreciar as similaridades e diferenças nos comportamentos sociais e seus significados, bem como rever conceitos de normalidade e anormalidade no desenvolvimento social da criança.

Os dois questionários empregados foram: 1) O Questionário de Qualidade da Amizade (Friendship Quality Questionnaire-Revised - FQQ) (Parker \& Asher, 1989) que contém 41 itens cuja escala de respostas é do tipo Likert ( $1=$ não é verdade a $5=$ é realmente verdade) e que acessam a qualidade da relação da criança com o seu melhor amigo (indicado por ela mesma); 2) Uma versão adaptada do Perfil de Autopercepção para Crianças (Self-Perception Profile for Children) (Harter, 1985) que possui 43 itens, para responder numa escala likert de 5 pontos $(1=$ nunca a 5 = sempre), e que acessa a percepção da criança sobre si mesma. Os dois instrumentos foram submetidos à Análise Fatorial Exploratória, com rotação varimax. Com relação ao FQQ, foram revelados três fatores: 1) Ajuda instrumental/direção/companhia $(\boldsymbol{\alpha}=0,94)$, com 21 itens, por exemplo, “ e eu ajudamos sempre um(a) ao outro(a) nas tarefas e outras coisas."; 2) Resolução de conflito/intimidade/validação $(\boldsymbol{\alpha}=0,87)$ com 12 itens, por exemplo, "Se e eu ficamos bravos(as) um(a) com o(a)

outro(a), nós sempre conversamos sobre como superar isto"; e 3) Conflito/traição $(\boldsymbol{\alpha}=0,78)$ com 6 itens, por exemplo "__ e eu ficamos bravos(as) um com o(a) outro(a) frequentemente." Os espaços em branco em cada questão eram preenchido, por cada participante, com o nome do seu melhor amigo(a).

No que se refere ao instrumento Perfil de Autopercepção para Crianças, três fatores foram agrupados: 1) Competência Acadêmica $(\boldsymbol{\alpha}=0,77)$, com 14 itens, por exemplo, "Na escola, mesmo que as perguntas sejam difíceis, eu costumo ter as respostas corretas.";
2) Aceitação Social $(\boldsymbol{\alpha}=0,78)$, com 11 itens, por exemplo, "Eu tenho muitos(as) amigos(as)."; e 3 ) Competência Atlética $(\boldsymbol{\alpha}=0,70)$, com 9 itens, por exemplo, "Pratico muito bem todos os tipos de esportes.".

\section{Procedimento}

Inicialmente foi feito contato com as escolas e a proposta de pesquisa foi submetida à apreciação e aprovação da direção e coordenadorias pedagógicas. Após obter permissão da escola, todas as crianças receberam dos pesquisadores o Termo de Consentimento Livre e Esclarecido - TCLE para ser lido e assinado pelos pais/cuidadores autorizando a participação de seus filhos na pesquisa. Participaram da amostra somente as crianças cujos pais/cuidadores assinaram o TCLE.

As crianças completaram os questionários administrados em grupo em suas salas de aula. Nos dois instrumentos (um sobre relações de amizade e outro acessando a autopercepção em relação a diferentes domínios do self), as crianças indicavam o grau de concordância com as afirmações contidas nos itens, em cada questionário. Durante a administração destas medidas, sempre estiveram presente no mínimo três pesquisadores. As informações sobre o projeto e as orientações sobre os instrumentos foram dadas, em todas as turmas, às crianças, sempre pela coordenadora do projeto. Durante o preenchimento, os pesquisadores ficavam circulando na sala de aula para tirar dúvidas ou dar esclarecimentos adicionais às crianças, quando necessário.

O projeto do qual se deriva este estudo foi submetido à análise do Comitê de Ética em Pesquisa com Seres Humanos da Universidade do vale do Rio dos Sinos (UNISINOS), tendo sido aprovado sob o parecer 038/2009 do dia 29 de maio de 2009.

\section{RESULTADOS}

Antes de proceder com as análises correlacionais propriamente ditas, uma série de comparações entre grupos, definidos pelo sexo e idade da criança, foi realizada a fim de investigar os possíveis efeitos dessas covariáveis sobre as principais variáveis em estudo. Para investigar se meninas e meninos difeririam em relação às dimensões da qualidade da amizade (ajuda instrumental/companhia/direção, resolução de conflitos/intimidade/validação e conflito/traição) foi empregado o Teste- $t$ para amostras independentes, uma vez que a distribuição dos escores mostrou-se normal. Nenhuma diferença estatisticamente significante foi observada para as três dimensões. O mesmo teste foi usado para investigar as possíveis diferenças 
de gênero para as dimensões de autopercepção (competência acadêmica, aceitação social e competência atlética). Desta vez, apenas foi encontrada uma diferença significativa para a dimensão competência atlética $[t(147)=2,44 ; p \leq 0,05]$. Especificamente, meninos sentem-se mais competentes atleticamente do que meninas (média $=32,66 ; \mathrm{DP}=6,20$ e média $=30,37$; $\mathrm{DP}=5,08$, respectivamente).

$\mathrm{Na}$ investigação da comparação de escores das mesmas variáveis para os dois grupos de idade (grupo $1=9$ e 10 anos e grupo $2=11,12$ e 13 anos) o teste-t revelou diferenças significativas $[t(145)=3,46 ; p \leq$ $0,001]$ para a dimensão competência acadêmica, indicando que crianças mais jovens sentem-se mais com- petentes do ponto de vista acadêmico do que crianças mais velhas (média $=52,40 ; \mathrm{DP}=7,68$ para o grupo 1 e média $=47,87$; $\mathrm{DP}=42$ para o grupo 2 ). Além disso, foi observada uma tendência de diferença entre os dois grupos etários para a dimensão percepção de aceitação social $[t(143)=1,66 ; p=0,98)$. Especificamente, crianças mais jovens tendem a perceberem-se mais bem aceitas do que crianças mais velhas em seu grupo de pares.

Em seguida, para testar as hipóteses centrais deste estudo, foram realizadas as análises correlacionais. $\mathrm{Na}$ Tabela 1 são apresentados os resultados referentes à Matriz de Correlação entre as variáveis estudadas.

Tabela 1

Correlações de Pearson Entre as Dimensões da Qualidade da Amizade e as Dimensões de Autopercepção

\begin{tabular}{cccc}
\hline & $\begin{array}{c}\text { Competência } \\
\text { acadêmica }\end{array}$ & $\begin{array}{c}\text { Aceitação } \\
\text { social }\end{array}$ & $\begin{array}{c}\text { Competência } \\
\text { atlética }\end{array}$ \\
\hline Ajuda instrumental/direção/companhia & $0,31^{* *}$ & $0,35^{* *}$ & $0,23^{* *}$ \\
Resolução de conflitos/intimidade/validação & $0,31^{* *}$ & $0,31^{* *}$ & $0,18^{*}$ \\
Conflito/traição & $0,18^{*}$ & 0,12 & 0,04 \\
\hline
\end{tabular}

Notas. * Correlação é significativa com valor de $\mathrm{p}<0.05$ (bicaudal)

** Correlação é significativa com valor de $\mathrm{p}<0.01$ (bicaudal)

Como é possível constatar, duas dentre as três dimensões do FQQ (ajuda instrumental/companhia/ direção e resolução de conflitos/intimidade/validação) correlacionaram-se positivamente com todas as dimensões relativas à autopercepção infantil. Assim, quanto mais a criança se percebe competente acadêmica e atleticamente, e bem aceita no grupo de pares, mais esta criança também percebe provisões positivas em suas amizades Por outro lado, a dimensão conflito/traição, considerada uma dimensão negativa da amizade, correlacio- nou-se apenas com competência acadêmica. Dessa forma, crianças que se percebem competentes do ponto de vista acadêmico parecem experimentar também mais conflitos com o melhor amigo(a).

Uma vez que houve uma diferença significativa entre meninos e meninas para competência atlética, optou-se por examinar, também, as relações entre essa variável e as variáveis relativas à qualidade da amizade, para os dois sexos separadamente. Os resultados são apresentados na tabela 2 .

Tabela 2

Correlações de Pearson Entre as Dimensões da Qualidade da Amizade e as Dimensões de Autopercepção de Competência Atlética

\begin{tabular}{ccc}
\hline & \multicolumn{2}{c}{ Competência atlética } \\
\hline Ajuda instrumental/direção/companhia & Meninas & Meninos \\
Resolução de conflitos/ intimidade/validação & $0,24 \dagger$ & $0,27^{*}$ \\
Conflito/traição & $0,25^{*}$ & 0,18 \\
\hline
\end{tabular}

Notas. * Correlação é significativa com valor de $\mathrm{p}<0.05$ (bicaudal)

** Correlação é significativa com valor de $\mathrm{p}<0.01$ (bicaudal)

† Tendência à correlação com valor de $\mathrm{p}<0.10$ (bicaudal) 
A análise correlacional por gênero permitiu que se compreendessem melhor os resultados da correlação geral, apresentada na tabela, para as variáveis competência atlética e qualidade da amizade. Meninos e meninas que se sentem competentes atleticamente encontram provisões distintas em suas amizades. Enquanto os meninos buscam em seus amigos uma fonte de ajuda instrumental/companhia/direção, as meninas buscam mais exercitar formas de resolver conflitos, de ter intimidade e validação de seus sentimentos. No entanto, vale notar que talvez estas diferenças não sejam tão acentuadas, já que foi observada uma forte tendência à correlação entre competência atlética e ajuda instrumental/companhia/direção também entre as meninas $(r=0,24 ; p=0,06)$. É provável que se a amostra de meninas fosse maior, tal correlação positiva seria confirmada também para meninas, indicando, assim, que meninos e meninas que se percebem competentes nos esportes, a princípio, percebem igualmente seus amigos como parceiros que fornecem auxílio e orientação nas atividades das quais participam. Entretanto, adicionalmente, meninas aproveitam nessas relações de amizade desenvolver habilidades interpessoais, por meio de estratégias que visem resolver conflito, criar intimidade e sentir-se validadas em seus sentimentos.

\section{DISCUSSÃO}

O objetivo do presente estudo foi investigar as múltiplas correlações entre as dimensões do da qualidade da amizade (Ajuda instrumental/direção companhia, Resolução de conflito/intimidade/validação e Conflito/traição) e as dimensões da Autopercepção (Competência Acadêmica, Aceitação Social e Competência Atlética) em crianças e pré-adolescentes. Além disso, foi examinado o impacto que as variáveis idade e gênero exerceriam sobre as variáveis em estudo.

\section{PERCEPÇÕES DE MENINOS E MENINAS ACERCA DA QUALIDADE DAS AMIZADES}

As análises revelaram que meninas e meninos percebem de forma similar as qualidades de suas amizades. Assim, tanto meninos quanto meninas buscam nas relações com seus amigos uma fonte de ajuda instrumental, companhia, direção, intimidade, validação. Esses resultados corroboram os achados de Stocker e Dunn (1990), os quais não revelaram diferenças na qualidade da amizade para ambos os grupos. Entretanto, contrapõem-se aos achados de Parker e Asher (1993) nos quais as amizades de meninos e meninas são diferentes, tendo o primeiro grupo relatado uma percepção menor de validação, apoio, ajuda e direção, intimidade e uma maior dificuldade para resolver conflitos, na comparação com as meninas.

Uma possível explicação para a similaridade entre as percepções de meninos e meninas acerca da função das amizades em suas vidas pode ser buscada nas mudanças ocorridas nas formas como os pais educam as crianças para o convívio social, em nossa cultura, atualmente. De acordo com Reppold, Pacheco, Bardagi e Hutz (2002), as últimas décadas do século XX experimentaram importantes transformações no que diz respeito aos modos de socialização parental. Essas mudanças no modo de educar os filhos refletem mudanças nas crenças e atitudes parentais relativas às necessidades e direitos da criança que, por sua vez, são influenciadas pela disseminação do conhecimento técnico-científico de especialistas do desenvolvimento e da educação (Biasoli-Alves, Caldana, \& Silva, 1997). As sociedades urbanas industrializadas, como é o caso da maioria das capitais brasileiras, foram aquelas que sofreram as alterações mais radicais no que diz respeito aos valores e as crenças sobre a parentalidade (Biasoli-Alves, 2002). Mais ainda (Reppold et al., 2002), a educação dos pais parece estar centrada na crença de que os filhos têm necessidades emocionais típicas da infância como de suporte emocional e de respeito pela individualidade e autonomia. Finalmente, estudos mais atuais têm mostrado que no Brasil, mães valorizam tanto crenças, valores e práticas parentais relacionadas com a autonomia e a interdependência de modo bastante similar (Vieira et al., 2010). Ou seja, ao mesmo tempo em que se espera que os filhos tenham sucesso pessoal e profissional na vida, são cultivados valores de respeito pelos outros.

Pode-se deduzir que crianças que vivenciam uma educação mais democrática, cujos modos de ação são mais indutivos do que coercitivos podem desenvolver o senso de empatia, intimidade e companheirismo em relação aos pares, assim como tornarem-se mais habilidosas para resolver conflitos nas relações de pares. De fato, na presente pesquisa, as médias dos escores para meninos e meninas em ajuda instrumental/companhia e direção, numa escala de 1 a 5 , foram de 3,49 (meninos) e 3,68 (meninas), enquanto que as médias de resolução de conflito/busca de intimidade e confiança foram de 3,38 (meninos) e 3,48 (meninas). Os escores médios, localizados acima do ponto médio indicam uma tendência para ambos os sexos encontrarem nas amizades essas qualidades positivas. Por outro lado, nem tudo é harmonioso na relação entre pa- 
res. Podem ocorrer situações de disputas entre os pares. Talvez em função da busca de identidade e autonomia, tanto meninos como meninas procuram, em algum momento defender seu próprio ponto de vista e conquistar um status social de dominância nas interações e relações com pares. Ao serem analisados os escores obtidos no presente estudo, pode-se confirmar a tendência similarmente alta de meninos (média de 3,87 ) e meninas (média de 3,89) ambos em escala de 5 pontos, a encontrarem em suas amizades uma fonte de conflito.

\section{COMO MENINOS E MENINAS SE PERCEBEM}

No que se refere às dimensões de autopercepção, meninos tendem a se sentir mais competentes atleticamente do que meninas. Esse resultado corrobora com os achados de Cole (1991), Hoge e McSheffrey (1990) e Villwock e Valentini (2007). Neste último estudo, além dos meninos se perceberem mais competentes atleticamente eles também demonstraram habilidades motoras mais competentes.

Em princípio, chama a atenção o fato de, neste estudo, meninas e meninos terem percepções semelhantes em relação a sua competência acadêmica e aceitação social, resultado que difere de outras pesquisas que apontam as meninas como mais competentes academicamente do que meninos (Biasoli-Alves \& Caldana 1992; Carvalho, 2004; Perez \& Urquijo, 2001). No entanto, esses estudos empregaram medidas que acessam a competência acadêmica das crianças através de seus cuidadores e professores e, portanto, essa percepção do outro pode não refletir a autopercepção infantil, tal como foi acessada no presente estudo. Outro estudo que também acessou todas as dimensões de autopercepção a partir da escala original de Harter (competência acadêmica, aceitação social, competência atlética, aparência física e, autovalor global) também não encontrou diferenças significativas entre meninas e meninos (Almeida et al., 2009), o que sugere que as meninas, mesmo sendo avaliadas pelos adultos a sua volta de modo mais favorável do que meninos quanto as suas competências infantis, de modo geral, percebem-se tão competentes quanto, e não mais, que os meninos.

\section{EFEITO DA IDADE SOBRE A AUTOPERCEPÇÃO INFANTIL}

No que diz respeito à hipótese de que a idade das crianças teria impacto nos escores de autopercepção, ela foi confirmada na dimensão competência acadê- mica. Constatou-se por meio dos resultados que crianças mais novas (de 9 e 10 anos de idade) sentem-se mais competentes academicamente do que crianças que estão na faixa etária entre 11 e 13 anos de idade. Estes resultados vão ao encontro dos dados obtidos por Almeida et al. (2009) nos quais as crianças da faixa etária mais nova apresentaram escores mais elevados de percepção de competência escolar.

Isso talvez ocorra porque as crianças mais jovens encontram-se na idade protocolar, ou até mesmos adiantados, para cursarem a $4^{\mathrm{a}}$ serie $\left(5^{\circ}\right.$ ano $)$ do ensino Fundamental. Por sua vez, as crianças de 11, 12 ou 13 anos de idade estão, teoricamente, defasadas em relação idade/série. Essa situação pode ocorrer por vários motivos, mas o que parece ser mais comum é a repetência de alguma série, por dificuldades escolares. Isso pode levar a criança a desenvolver uma percepção desfavorável de sua competência acadêmica. Além disso, também, é possível supor que alunos dessa última faixa etária já se encontram em um período no qual surgem novas demandas no campo social (número de amizades, relações românticas, por exemplo). Dessa forma, interesses conflitantes podem levar o pré-adolescente a descuidar das tarefas escolares e prejudicar seu desempenho escolar, levando-o a perceber-se menos competente academicamente.

\section{CORRELAÇÕES ENTRE A QUALIDADE DAS AMIZADES E A AUTOPERCEPÇÃO}

No que diz respeito às análises correlacionais, foco central do presente estudo, as hipóteses foram parcialmente confirmadas. Crianças que veem nas suas relações de amizade uma fonte de ajuda instrumental, de companhia e de direção tendem a se perceber acadêmica e atleticamente competentes e bem aceitas socialmente. Da mesma forma, crianças que encontram nas amizades um espaço privilegiado para resolver conflitos, buscar intimidade e validação de seus sentimentos também têm percepções positivas acerca de si. Esses resultados corroboram com os achados de Bukowski, Hoza e Boivin (1993) os quais relataram que os escores de amizade estavam relacionados com autoestima e competência percebida. Tem sido registrado, em vários estudos, que a amizade é fonte de adaptação e autoestima nas crianças (Garcia, 2005; Rubin et al., 2005). A percepção de qualidade positiva das amizades (ex: sentir que tem apoio, companhia, que é valorizada, que pode compartilhar afeto e intimidade) parece funcionar como um fator de valorização pessoal, de reforço da autoestima e de proteção social. 
Em relação à percepção de competência atlética, examinados para meninos e meninas, separadamente, foi observado que os meninos que se percebem mais competentes do ponto de vista atlético tendem também a encontrar nas amizades qualidade positivas como ajuda instrumental, companhia e direção. As meninas que se sentem competentes nessa área percebem-se, também, hábeis para resolver conflitos e encontram nas amizades fontes de intimidade e validação afetiva, ainda que também tenha sido observada uma forte tendência para correlação entre percepção de competência atlética e ajuda instrumental/companhia/direção também entre as meninas. Estas especificidades de gênero podem ser explicadas a partir das diferenças nos jogos e discursos característicos dos grupos de meninos e meninas citadas por diferentes autores (Archer, 1992; Maccoby, 1988; Souza \& Rodrigues, 2002; Sutton-Smith, 1971). Os meninos, segundo Maccoby (1988), emitem mais informações e direções durante os jogos. Assim, é possível supor que é durante a prática de esportes, com fins lúdicos e competitivos (numa partida de futebol, por exemplo), que os meninos descubram companheiros prediletos e encontrem neles uma importante fonte de ajuda instrumental e de orientação de como se comportar socialmente. Já o jogo das meninas, segundo Archer (1992) é caracterizado por ser mais cooperativo, fortemente baseado na fala e no estabelecimento de interações amigáveis, de modo a se criar e manter relações mais íntimas e recíprocas. Com base nisso, é plausível pensar que entre meninas ser boa nos esportes significa conseguir estabelecer boas relações com as companheiras esportivas, não brigar, saber perder, por exemplo. Assim, mais do que a destreza técnica de jogar, entre meninas pode entrar em cena a habilidade social de interagir positivamente com outras meninas de seu time.

\section{CONCLUSÃO}

A partir dos resultados obtidos neste estudo, pode-se concluir que o modo como a criança avalia o papel da amizade em sua vida parece estar intrinsecamente relacionado com o modo como avalia sua competência social, neste caso específico, sua competência acadêmica e atlética e aceitação social. O modo como a criança se percebe tem, por sua vez, implicações importantes para o seu bem-estar social e psicológico.

Embora os dados tenham revelado diferenças para meninos e meninas apenas para uma dimensão da autopercepção, parece haver diferenças em como estes dois grupos se relacionam com seus amigos e como eles se percebem através das suas amizades. Isso pode servir como base para outros estudos, que visem a uma melhor compreensão destas diferenças no comportamento social de meninos e meninas que orientem o exercício de formas mais adequadas e mais adaptativas de inserção e trabalho com estas crianças, principalmente no ambiente escolar. As diferenças nas correlações encontradas para as faixas etárias podem revelar a necessidade de investigação na área da educação, sobre o impacto e as implicações dessas diferenças nas relações estabelecidas entre os colegas e no desempenho acadêmico e no bem estar social e psicológico da criança.

As contribuições do presente estudo trazem avanços para a área do desenvolvimento, contudo, é importante destacar algumas limitações. Uma delas, de ordem metodológica, diz respeito à fonte de informações. Por estar circunscrito à percepção das crianças, não foram examinadas as competências, nem a qualidade das amizades das crianças, pela ótica de outros agentes sociais significantes, isto é, pela percepção dos pares, dos pais ou cuidadores e dos professores Da mesma forma, ao falar das amizades, não foi possível confirmar sua reciprocidade, ou seja, verificar se a criança indicada por um participante como seu/sua melhor amigo/a, também a indicava como melhor amigo/a. O fato de que a qualidade da amizade possa estar sendo avaliada sobre relações que talvez não sejam recíprocas, aponta para a necessidade de comparar relatos de grupos de amizades recíprocas e não recíprocas e suas implicações em outros construtos relacionados. Além disso, sugere-se incluir, em novos estudos, outros fatores de ordem sociodemográfica, tais como, nível de escolaridade, disponibilidade de tempo dos cuidadores com a criança e arranjos familiares, a fim de que a contribuição de cada estudo ajude a compor um olhar mais amplo e aprofundado sobre as variáveis relacionadas aos fenômenos estudados.

Em termos da amostra, é necessário ampliar os locais de coleta de dados, envolvendo não somente escolas públicas, mas também particulares para se obter um quadro mais representativo da população escolar. Nesse sentido, recomenda-se ampliar também as regiões do país, uma vez que os dados da presente pesquisa foram coletados apenas em uma cidade do sul do Brasil. De qualquer forma, os resultados obtidos na presente pesquisa são consistentes e indicam a relevância de se estudar a relação entre a qualidade das amizades e a autopercepção.

Nesse sentido, é importante destacar que as pesquisas atuais tendem a se concentrar mais no estudo dos 
comportamentos antissociais e internalizantes, bem como na indicação de diferentes maneiras para a eliminação de comportamentos negativos (por exemplo, o bullying), talvez por serem mais salientes e perturbadores. Neste estudo, no entanto, o foco foi o estudo de aspectos saudáveis das relações das crianças, e contribuiu para identificar quais as variáveis são mais importantes nessa dinâmica, auxiliando pais, educadores e profissionais da área da saúde. Se a qualidade das amizades tem um impacto positivo sobre os diferentes domínios da autopercepção e, consequentemente, nas interações que eles estabelecem nos seus diferentes ambientes, incentivar e ensinar as crianças a interagir com seus pares de uma maneira mais positiva contribui não apenas para o desenvolvimento de comportamentos pró-sociais, como também influencia de forma benéfica no desenvolvimento cognitivo, social e afetivo.

\section{REFERÊNCIAS}

Almeida, G., Valentini, N. C., \& Berleze, A. (2009). Percepções de competência: Um estudo com crianças e adolescentes do ensino fundamental. Movimento, 15, 71-97.

Archer, J. (1992) Childhood gender roles: Social context and organization. In H. McGurk (Ed.), Childhood social development: Contemporary perspectives (pp. 31-61). Hove, England: Lawrence Erlbaum.

Biasoli-Alves, Z. M. M. (2002). A questão da disciplina na prática de educação da criança no Brasil, ao longo do século XX. Veritati, 2, 243-259.

Biasoli-Alves, Z. M. M., \& Caldana, R. H. L. (1992). Práticas educativas: A participação da criança na determinação de seu dia-a-dia. Psicologia: Teoria e Pesquisa, 8, 231-242.

Biasoli-Alves, Z. M. M., Caldana, R. H. L., \& Silva, M. H. G. F. D. (1997). Práticas de educação da criança na família: A emergência do saber técnico-científico. Revista Brasileira de Crescimento e Desenvolvimento Humano, 7, 49-62.

Bukowski, W. M., Hoza, B., \& Boivin, M. (1993). Popularity, friendship, and emotional adjustment during early adolescence. New Directions for Child and Adolescent Development, 60, 2337.

Carvalho, M. P. (2004). Quem são os meninos que fracassam na escola? Cadernos de Pesquisa, 34, 231-252.

Cecconello, A. M., \& Koller, S. H. (2000). Competência social e empatia: Um estudo sobre a resiliência com crianças em situação de pobreza. Estudos de Psicologia (Natal), 5, 71-93.

Cole, D. A. (1991). Change in self-perceived competence as a function of peer and teacher evaluation. Developmental Psychology, 27, 682-688.

Eder, D., \& Hallinan, M. T. (1978). Sex differences in children's friendships. American Sociological Review, 43, 237-250.

Erikson, E. H. (1976). Infância e sociedade (G. Amado, Trans.). Rio de Janeiro: Zahar.
Fitzerald, A., Fitzerald, N., \& Aherne, C. (2012). Do peer matter? A review of peer and/or friends' influence on physical activity among American adolescents. Journal of Adolescence, 35, 941958.

Garcia, A. (2005). Psicologia da amizade na infância: Uma introdução. Vitória: GM.

Garcia, A., \& Pereira, P. C. C. (2008). Amizade na infância: Um estudo empírico. Revista de Psicologia da Vetor Editora, 9, 25-34.

Harter, S. (1982). The perceived competence scale for children. Child Development, 53, 89-97.

Harter, S. (1985). The self-perception profile for children. Denver, CO: University of Denver.

Harter, S. (1999). The construction of the self: A developmental perspective. New York: Guilford Press.

Hoge, R. D., \& McSheffrey, R. (1990). An investigation of selfconcept in gifted children. Exceptional Children, 57, 238-245.

Maccoby, E. (1988). Gender as a social category. Developmental Psychology, 24, 755-765.

Mondell, S., \& Tyler, F. B. (1981). Child psychosocial competence and its measurement. Journal of Pediatric Psychology, 6, $145-154$.

Osterrieth, P. A. (1980). A desagregação da subjetividade primitiva. In P. A. Osterrieth (Ed.), Introdução à psicologia da criança (pp. 111-137). São Paulo: Nacional.

Parker, J., \& Asher, S. (1989). Friendship Quality QuestionnaireRevised: Instrument and administrative manual. State College, PA: Penn State University.

Parker, J. G., \& Asher, S. R. (1993). Friendship and friendship quality in middle childhood: Links with peer group acceptance and feelings of loneliness and social dissatisfaction. Developmental Psychology, 29, 611-621.

Pérez, M. V., \& Urquijo, S. (2001). Depresión em adolescents: Relaciones com el desempeño académico. Psicologia Escolar e Educacional, 5, 49-58.

Reppold, C. T., Pacheco, J., Bardagi, M., \& Hutz, C. S. (2002). Prevenção de problemas de comportamento e desenvolvimento de competências psicossociais em crianças e adolescentes: Uma análise das práticas educativas e dos estilos parentais. In C. S. Hutz (Ed.), Situações de risco e vulnerabilidade na infância e adolescência: Aspectos teóricos e estratégias de intervenção (pp. 9-51). São Paulo: Casa do Psicólogo.

Rubin, K. H., Coplan, R., Chen, X., Buskirk, A., \& Wojslawowicz, J. C. (2005). Peer relationships in childhood. In M. Bornstein \& M. Lamb (Eds.), Developmental psychology: An advanced textbook (pp. 469-512). Hillsdale, NJ: Erlbaum.

Smith, A. L., Ullrich-French, S. Walker, E., \& Huerley, K. S. (2006). Peer relationship profiles and motivation in youth sport. Journal of Sport \& Exercice Psychology, 28, 362-382.

Souza, F., \& Rodrigues, M. M. P. (2002). A segregação sexual na interação de crianças de 8 e 9 anos. Psicologia: Reflexão $e$ Crítica, 15, 489-496.

Stocker, C., \& Dunn, J. (1990). Sibling relationships in childhood: Links with friendships and peer relationships. British Journal of Developmental Psychology, 8, 227-244. 
Sutton-Smith, B. (1971). Play, games and controls. In J. P. Scott \& S. F. Scott (Eds.), Social control and social change (pp. 7398). Chicago, IL: University of Chicago Press.

Sutton-Smith, B., \& Rosenberg, B. G. (1971). Sixty years of historical change in the game preference of American children. In R. E. Heron \& B. Sutton-Smith (Eds.) Child's play (pp. 1850). New York, NY: Wiley.

Vieira, M. L., Seidl-de-Moura, M. L., Macarini, S. M., Martins, G. D. F., Lordelo, E. R., Tokumaru, R. S., \& Oliva, A. D. (2010). Autonomy and interpedendence: Beliefs of Brazilian mothers from state capitals and small towns. The Spanish Journal of Psychology, 13, 816-824.
Villwock, G., \& Valentini, N. C. (2007). Percepção de competência atlética, orientação motivacional e competência motora em crianças de escolas públicas: Estudo desenvolvimentista e correlacional. Revista Brasileira de Educação Física e Esporte, $21,245-257$.

\section{Nota:}

1 Agradecemos às equipes pedagógicas das escolas, aos professores, às crianças e aos pais que participaram da pesquisa. Também nosso agradecimento para a profa. Dra. Carolina Saraiva de Macedo Lisboa, da UNISINOS (RS), pela contribuição no processo de construção do projeto. A presente pesquisa teve financiamento do CNPq. Este estudo deriva da tese de doutorado da segunda autora, que foi bolsista da CAPES. 